\title{
Presentation of the new Chapter on Regenerative Medicine and Surgery
}

\author{
Michele L. Zocchi ${ }^{1}$ (D) \\ Received: 15 July 2019 / Accepted: 24 July 2019/Published online: 21 October 2019 \\ (C) Springer-Verlag GmbH Germany, part of Springer Nature 2019
}

Sir,

It is indeed a great honor to be appointed Section Editor of a new section fully dedicated to Regenerative Surgery and Medicine.

This great innovation, supported and introduced by our Chief Editors Prof. Horacio Mayer and Prof. Paolo Persichetti, is really unique among all the other International Journals of Plastic Surgery and will expand our horizons into this new field of research that should be considered the most promising in our specialty.

The rapid growth and acceptance of Regenerative Medicine and Surgery as a variety of disease entities spanning all specialties is in no small part due to the tireless work and efforts of pioneering plastic surgeons.

The goal that regenerative medicine sets itself can be achieved in a very short time if there is the will and the ability to create a "governance of research" focused to stimulate an interdisciplinary collaboration that involves all the main actors of the scientific community, from medical professionals to those of basic science, molecular biology, and bioengineering.

We do expect a great interest in the release of many new articles, both on basic science and clinical applications, devoted to regenerative technologies and highlighting the prominent role of plastic surgeons as the historic experts in supplying the most abundant, reliable, and efficient source of regenerative components: the adipose tissue.

I want to ensure you that I will pursue this task with my full commitment and dedication. Very soon other world-renowned experts in this field will join me in the newly created editorial board to ensure a continuance of the stellar standards our journal has come to represent.

As my very first action and in an effort to open this important discussion, I propose to you an extensive compendium of my personal considerations based on experience gained in over 25 years in this specific field.

I hope that is going to help in clarifying a few points of common confusion as well as start a constructive discourse based on historical facts and solid scientific data.

Prof. Michele L. Zocchi M.D. Ph. D.

Publisher's note Springer Nature remains neutral with regard to jurisdictional claims in published maps and institutional affiliations.

Michele L. Zocchi

info@michelezocchi.com

1 Institute of Plastic and Reconstructive Surgery of Medical University of Padua, Via 8 Febbraio 1848, 2, 35122 Padova, PD, Italy 